Discussion on Paper No. 6869*

\title{
Calculation of flow at a free overfall by relaxation method
}

\author{
by
}

E. Markland, Ph.D., A.M.I.C.E.

Mr J. E. Acton (Assistant Resident Engineer, Gloucestershire County Council) wrote that he had found the Paper extremely explicit except for part of $\$ 9$, in which the Author stated that 'the discrepancy previously noted between the earlier relaxation solution and experiments has been almost entirely removed by the present calculations'. Perhaps Dr Markland would explain whether or not this increased accuracy was caused solely by the use of finer nets than those which were practical without the aid of a computer. Could he also indicate the theory behind the extrapolation to determine the value of $d_{\mathrm{c}}$ for an infinitely fine net? It appeared that if a correlation existed between the values of $d_{0}$ for various values of $a$ it was unnecessary to use finer nets.

12. The Paper was particularly interesting to Mr Acton as he had produced work concerned with a parallel problem: that of the torsional analysis of thick-walled prismatic members. ${ }^{7}$ At first glance the problems did not appear to be in the least similar, but the governing equation of the torsion problem was Poisson's equation:

$$
\frac{\partial^{2} \phi}{\partial x^{2}}+\frac{\partial^{2} \phi}{\partial y^{2}}+2 G \theta=0 \quad \text {. . . . . . . }
$$

which might be compared with equation (5).

13. The components of shear stress caused by torsion were given by:

$$
\tau_{x z}=\frac{\partial \phi}{\partial y}, \quad \tau_{y z}=-\frac{\partial \phi}{\partial x} \quad . \quad . \quad . \quad . \quad .
$$

which was comparable to equation (6).

14. The solution of the torsion problem by the relaxation method was also relatively simple to programme for a digital computer. In the case of his work a Standard Telephones computer was used, and it was found that the programming itself was a most intriguing exercise. It had to be emphasized that the computer could take no decisions of its own accord, and all eventualities had therefore to be considered when writing the programme. It was surprising and chastening to discover the number of steps which were taken or omitted without consideration when performing routine calculations, and programming was a sure way to clarify any analytical procedure.

Professor Ch. Jaeger (English Electric Co. Ltd, Rugby) wrote that the flow over a free overfall or broad-crested weir was one of the simplest which could be considered in open channel hydraulics. It had attracted the attention of many specialists, but the problems connected with it had nevertheless never been solved to their entire satisfaction. In $\S 3$ the Author stated clearly that he assumed the flow to be frictionless, and implicitly assumed that at the far upstream end of the flow all the velocities were parallel (horizontal) and identical. These simplifying assumptions made treatment by the potential flow theory easier. Results of the calculation were shown

* Proc. Instn civ. Engrs, 1965, 31 (May) 71-78. 
to be in very good agreement with measurements. Many previous writers had neglected to introduce the momentum equation: this Author had, and was to be commended for taking this important step correctly.

16. Most experts would agree that friction losses over the short distance ED (Figs 1,2 ) could be neglected, but could the friction losses upstream of cross-section EA (Fig. 1) be equally neglected? They caused the uneven distribution of velocity in the cross-section EA. This was often taken into account by introducing a coefficient $\alpha=\frac{1}{\mathrm{~A} U_{\mathrm{m}}^{3}} \int_{\mathrm{A}} U^{3} d$ A for energy consideration and a coefficient $\alpha^{\prime}=\frac{1}{\mathrm{~A} U_{\mathrm{m}}^{2}} \int_{\mathrm{A}}$ $U^{2} d \mathrm{~A}$ for the momentum equation. In these definitions of $\alpha$ and $\alpha^{\prime}, U_{\mathrm{m}}=$ the average velocity, $U_{\mathrm{m}}=Q /$ A when the discharge $Q$ passes through the cross-sectional area $\mathrm{A}$. The Author's approach did not account for the uneven distribution of velocities, but most probably this could be done.

17. Many years ago, the writer had dealt with the same problem by writing the equation of energy and the equation of momentum for a cross-section (section EA in Fig. 1) upstream of the brink, and for the brink section (section $\mathrm{DD}_{1}$ in Fig. 2). He additionally accepted that the theorem of the centre of gravity could be applied to the jet passing through $\mathrm{DD}_{1}$. There were several methods for applying this theorem: only the easiest solution was published. ${ }^{8,8,10}$ However the object was not to discuss this solution but to mention that too often the uneven distribution of velocities was not given the place and importance it deserved in fluid mechanics.

18. It could be shown that the uneven distribution of velocities was linked to the dispersion of energies in any cross-section. If the energy $\mathrm{Hz}$ at any level $z$ was

$$
H_{\mathrm{z}}=H a+\Delta H
$$

where $H \sigma$ was the average energy level in the cross-section, then a dimensionless coefficient

$$
\epsilon=\frac{2 g}{\mathrm{~A} U_{\mathrm{m}}^{2}} \int_{\mathrm{A}} \Delta H d \mathrm{~A}^{11,12} \quad . \quad . \quad . \quad . \quad .
$$

could be defined, which can be shown to be

$$
\epsilon=\alpha-\alpha^{\prime}
$$

Schröder had shown that $\epsilon$ was linked with the $\lambda$ value of friction losses as given Nikuradse. For smooth pipes (Nikuradse-Schröder):

$$
\lambda=-0.003+0.577 \epsilon \cong 0.50 \epsilon,
$$

and for rough pipes (Nikuradse-Schröder):

$$
\epsilon=1.50 \lambda(1-0.194 \sqrt{\lambda}) \cong 1.5 \lambda \text {. }
$$

19. These remarks concerned the physics of flow in open channels in contrast to the mathematical approach of the Author. Both aspects of the problem were equally important.

Mr A. J. M. Harrison and Dr A. J. Brewer (Hydraulics Research Station, Wallingford) submitted that the numerical solutions obtained by Dr Markland for the flow of an ideal fluid at a free overfall in a horizontal channel showed remarkable agreement with experimental results. With a Froude number of unity in the approach channel the ratio of brink depth to apparent critical depth of 0.720 agreed very closely with the experimental values of 0.719 determined by Carstens, ${ }^{14}$ and 0.704 by Delleur, Dooge, and Gent, ${ }^{15}$; as well as that of 0.715 by Rouse ${ }^{1}$ quoted by the Author. He asked why there was a discrepancy between Rouse's experimental results and the calculations of Southwell and Vaisey." His own solution demonstrated that there should have been little discrepancy, and that the remaining differences in nappe shape could easily be explained by friction and head loss in the channel. However, experimental results given in references (14) and (15) and those of Paderi ${ }^{16}{ }^{17}$ indicated that the ratio varied considerably in sloping channels. 


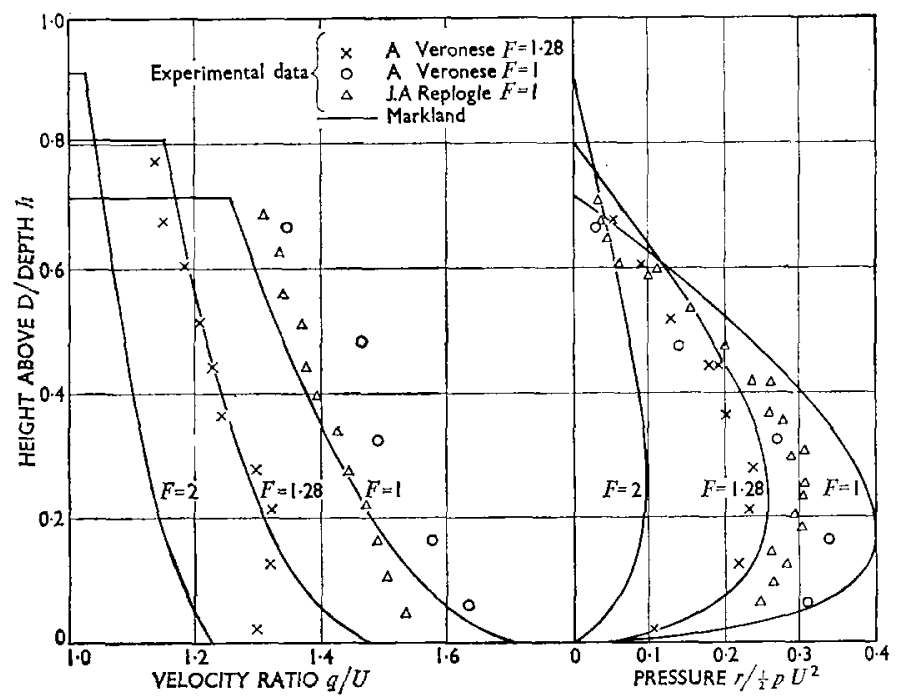

FIG. 5: VelocitY AND PRESSURE DISTRIBUTIONS AT THE BRINK

21. The writers had compared the velocity and pressure profiles computed by Dr Markland with values extracted from figures presented by Veronese ${ }^{18}$ and Replogle ${ }^{19}$ (Fig. 5) in which the lines for $F=1.28$ were interpolated from those for $F=1,2$, and 4 in Fig. 4. The agreement between the experimental and computed velocity profiles was quite good but that of the pressure distribution was poorer, especially at $F=1$. The reason for this was not obvious but it could be due to frictional effects in the region of the brink. Both experimental plots for $F=1$ had subcritical flow upstream but the values of $U$ and $h$ used were calculated from the discharge using critical-flow theory.

22. The writers were concerned with the possible use of the free overfall as a gauging device in the field. This seemed to present some practical difficulties. Although for $F<1$ the overfall brink was the control section, the depth could only be measured by observation of the water surface because of the non-hydrostatic pressure distribution; continuous automatic recording was therefore impracticable. Furthermore, the slope of the water surface was great at this point, making visual observation difficult.

23. In an alternative method of measurement, suggested by Paderi, ${ }^{20}$ the apparent critical depth $y_{\mathrm{c}}\left(=\left\{q^{2} / g\right\}^{1 / 3}\right)$ was measured at a distance $x_{0}=3 y_{0}$ upstream of the brink by means of an inclined scale, this distance having been obtained experimentally. This method avoided reading the water depth where the surface slope was great, but still involved, for most practical cases, a visual observation of water level. It was also by no means certain that the value of $x_{\mathrm{c}} / y_{\mathrm{o}}$ was independent of channel roughness. Carstens and Carter ${ }^{21}$ in their Fig. 3 showed a variation of this ratio from 1.8 to 6 for $\left(s_{0}-s_{0}\right)$ between 0.016 and 0 where $s_{0}$ was the bed slope and $s_{0}$ the critical slope. Kandaswamy and Rouse ${ }^{22}$ obtained the result $x_{0} / y_{0}=4$ for a horizontal channel while Carstens $^{14}$ obtained a value of 2.5 for the same case. It also seemed likely that the presence of waves on the water surface affected the position of the apparent critical section in some cases. The profiles plotted by both Paderi ${ }^{20}$ and Hamid ${ }^{23}$ showed surface undulations of considerable amplitude. 
24. A possible solution to the problem of obtaining a continuous record might be to situate a bed pressure tapping at a distance of 3 or 4 times $y_{c}$ (max.) upstream of the brink and to make a correction for the head loss between the tapping and the brink at lower discharges. Some experiments directed towards developing such a measuring device were at present in progress at the Hydraulics Research Station, Wallingford.

Professor Theodor Strelkoff (Assistant Professor of Water Science and Civil Engineering, University of California) wrote that to him a typically 'hydraulic' approach to predicting a field of flow consisted of viewing it as a series of cross-sections, characterized by successive values of some such flow parameter as depth, average velocity, specific energy, etc. This 'one-dimensional' approach was particularly suited to calculating gradually varied flows, where streamline curvature was negligible, but gravitational forces and fluid resistance played a leading role.

26. Classical hydrodynamics, on the other hand, including the free-stream techniques of Kirchhoff and Helmholtz, while taking streamline curvature into account, had not proved adaptable to the inclusion of important gravitational effects.

27. The Author's approach took into account both flow curvature and gravity, while energy losses and rotationality present in a real flow were neglected. Fortunately, in a rapidly varying convergent flow these were minor factors, as was shown by the Author's comparison of calculated and experimental brink depths, and by the writer's own work using a superposition of theoretical and experimental weir-flow profiles. $^{24}$ A complete picture of a real flow could be obtained simply by pasting together the profile of the gradually varied flow or 'backwater curve' and the profile of rapidly varied flow in the vicinity of a control structure.

28. Analysis of gradually varied flow had been greatly enhanced by the use of the specific energy/depth diagram, introduced by Boris Bakhmeteff ${ }^{25}$ in 1912 . This well-known diagram showed possible states of parallel flow and, as such, could not be used to chart the course of flow through successive sections of a curvilinear zone, as at a fall.

29. The writer had devised a generalization of Bakhmeteff's diagram, which included the effects of streamline curvature and surface inclination and was therefore valid for every section in any free-surface flow. By means of this diagram it could readily be shown that unity was the lower limit of the Froude number of approach to a brink at the end of a channel whose slope just equalled the rate of energy loss in the flow.

30. Following as closely as possible the Author's notation, the total head $H$ relative to the elevation of the bounding streamline directly below could be expressed for any point on the upper free surface as

$$
H=d+q^{2} / 2 g
$$

where $d$ was the vertical depth of flow and $H=y(\phi, 0)$. The local speed $q$ could be written in terms of discharge per unit breadth $Q=U h$, the angle $\theta$ to the horizontal made by the local tangent to the free surface, and a factor $\alpha$ depending upon the vertical spacing of the local streamline relative to the average vertical spacing and defined by $\alpha=\frac{u}{Q / d}$. After multiplication of both sides of equation (32) by $d^{2} / H^{3}$ and a simple rearrangement, the following expression was obtained:

$$
\left(\frac{d}{H}\right)^{2}-\left(\frac{d}{H}\right)^{3}=\frac{\alpha^{2} Q^{2}}{\cos ^{2} \theta \cdot 2 g H^{3}} \quad \text {. . . . . . . }
$$

31. Points on the lower portion of the graph of equation (33) (see Fig. 6) represented shooting flows; those on the upper branch, tranquil flows. It was convenient to designate those flows for which the abscissa assumed its maximum possible value of $4 / 27$ as critical; under such conditions, the vertical depth was two-thirds the local value of specific head $H$. 


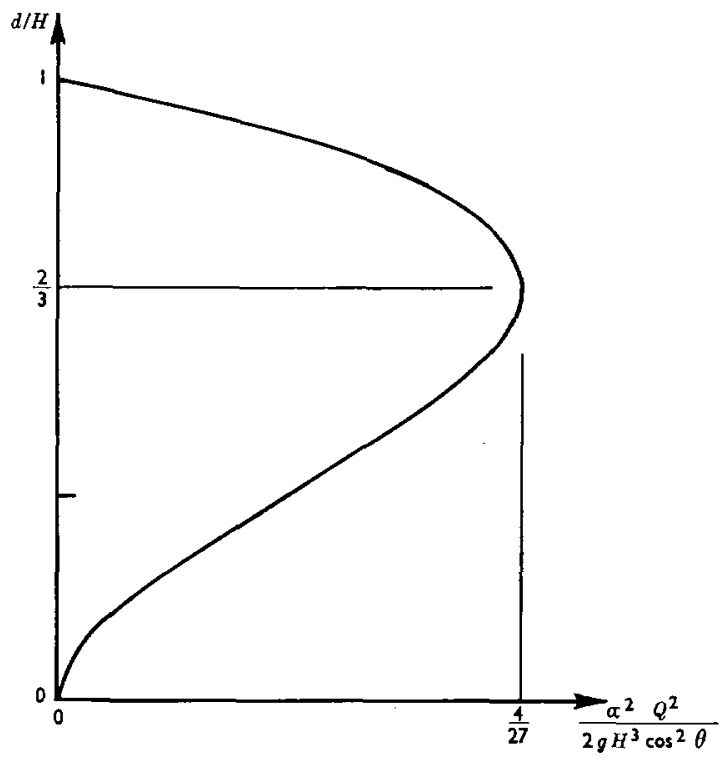

Fig. 6: Modified SPECIFIC-HEAd DIAGRAM

32. If the free overfall was considered (Fig. 1(a)) in the light of equation (33) and jts graph, then successive sections in the flow were identified by various values of the term $\alpha^{2} Q^{2} / \cos ^{2} \theta \cdot 2 g H^{3}$. Since $Q$ and $g$ were constant, this term was only affected by variations in $\alpha, \theta$, and $H$. Far downstream below the brink, clearly, $H$ was very large, and $\alpha^{2} Q^{2} / 2 g H^{3} \cos ^{2} \theta$ was very small. Successive sections of the flow were therefore represented by successive positions of a point on the lower leg of the curve of Fig. 6 gradually approaching the origin. If the Froude number of the essentially parallel flow approaching the brink was greater than unity, this was indicated on the graph by values $\alpha^{2} Q^{2} / 2 g H^{3} \cos ^{2} \theta<4 / 27(\alpha=\cos \theta=1)$ and $d / H<2 / 3$, i.e., by a point on the lower leg of the curve. The variations in $\alpha, \theta$, and $H$ along the flow were such that the point remained on the lower leg throughout.

33. Let it be supposed that the approaching parallel flow was tranquil with $F<1$. Since the flow at successive sections was increasingly concave as it approached the brink, streamline spacing was increasingly greater at the top relative to the average spacing, i.e., $\alpha$ decreased monotonically from its unity value. At the same time, $H$ was constant all the way to the brink. Thus if variations in $\cos \theta$ were sufficiently small, the abscissa value of the corresponding point in Fig. 6 must decrease, and if, in accordance with the above supposition, its far-upstream location was on the upper leg of the graph, the point could only move further up the graph as the brink was approached, indicating an ever increasing depth of flow, a situation at variance with the case (Fig. 1(a)) being analysed. Thus, the limiting location for the starting point of Fig. 6 corresponding to the section AE (Fig. 1(a)) was at the nose of the graph where $d / H=2 / 3$ and $F=1$. From this point as the abscissa value decreased, the point moved down the lower leg, at first slowly, by virtue of the variation in $a^{2} / \cos ^{2} \theta$ and then more rapidly, as beyond the brink $H$ increased without limit.

34. Figure 6 could be used to elucidate Boussinesq's stability principle (cited by 10 
Jaeger ${ }^{11}$ ) which stated that flow in overfall devices occurred at the maximum discharge possible with the available head. Starting with the known fact that flow was supercritical on the downstream side of the structure (on the lower leg of Fig. 6) and subcritical on the upstream side (upper leg), since every flow section in between was characterized by a point on the graph, at some section $\alpha^{2} Q^{2} / 2 g H^{3} \cos ^{2} \theta$ must achieve its maximum value of $4 / 27$. The interrelationship between solid boundaries and gravitational forces found, for example, by the Author's methods, determined the distribution along the flow of $\alpha, \theta$, and $H$, and thus controlled the actual value of $Q$.

35. As a corollary, the flow in an overfall device $Q$ could be increased for a given $H$ if the internal velocity distribution could be modified to decrease $\alpha$, i.e., if the topmost velocities could be decreased relative to the average, say, by increased downward curvature. Measurements taken by the writer from the Author's profile (Fig. 3, $F=1$ ) showed that $\alpha$ and $\theta$ varied in such a way that the control section was actually infinitely far upstream. Closer to, and at the brink $\alpha / \cos \theta<1$, the flow was already supercritical and actually more discharge could pass at the given head than was being supplied from upstream. Conversely, it should be possible to decrease the specific head a small amount at the brink by introducing a low sill without the water level upstream rising. Unfortunately physical instabilities and mathematical instabilities in near-critical flows made testing this contention either in the laboratory or in theory very difficult.

36. The writer was very much heartened by the Author's experience that inclusion of a complex, non-linear boundary condition in the system of simultaneous finitedifference equations for which a solution was sought did not subvert the convergence of the simple iterative scheme used to relax their residuals. The writer was particularly grateful to the Author for supplying an accurate solution to a long-standing problem in the field of free-surface gravity flows, wherein a number of new methods was being tested. ${ }^{26-30}$

The Author expressed his thanks to the contributors to the discussion, which, taken with the considerable number of additional references, greatly enhanced the value of the Paper.

38. In reply to Mr Acton's enquiry about the extrapolation to an infinitely fine net, the calculated depth $d_{\mathrm{c}}$ at the brink had been taken to be related to the mesh size $a$ of the calculation by an expression of the form

$$
d_{\mathrm{c}}=d_{\mathrm{co}}+e a^{\mathrm{n}}
$$

in which $d_{00}$ is the extrapolated value and $e$ and $n$ are assumed to be constant. No theoretical justification was known for this procedure, but its use appeared to the Author to be reasonable, especially where $d_{0}$ changed only slightly with change in $\alpha$. The use of finer nets in the present calculations was only partially responsible for the improvement in accuracy over that obtained in previous solutions, since the present technique avoided the loss of accuracy associated with the use of irregular stars.

39. The effect of uneven velocity distribution in the approaching flow was discussed by Professor Jaeger; the potential flow treated in the Paper, had uniform speed over the upstream cross-section and in this respect did not correctly represent the flow of a real liquid. There was an indication in Fig. 5 that the measured velocity close to the brink $\mathrm{D}$ was noticeably less than the calculated value, and this was presumably because of a reduction in the velocity near the bed in the approach section. The Author would concur with Professor Jaeger in his view that both physical and mathematical approaches to problems of channel flow were important.

40. Mr Harrison and Dr Brewer drew attention to much valuable work previously unknown to the Author. It was gratifying to find reasonable agreement between the calculated pressures and velocities and measured values, although the experimental results of Fig. 5 were clearly subject to considerable scatter. It had previously not occurred to the Author that the interval between solutions for $F=1$ and for $F=2$ 


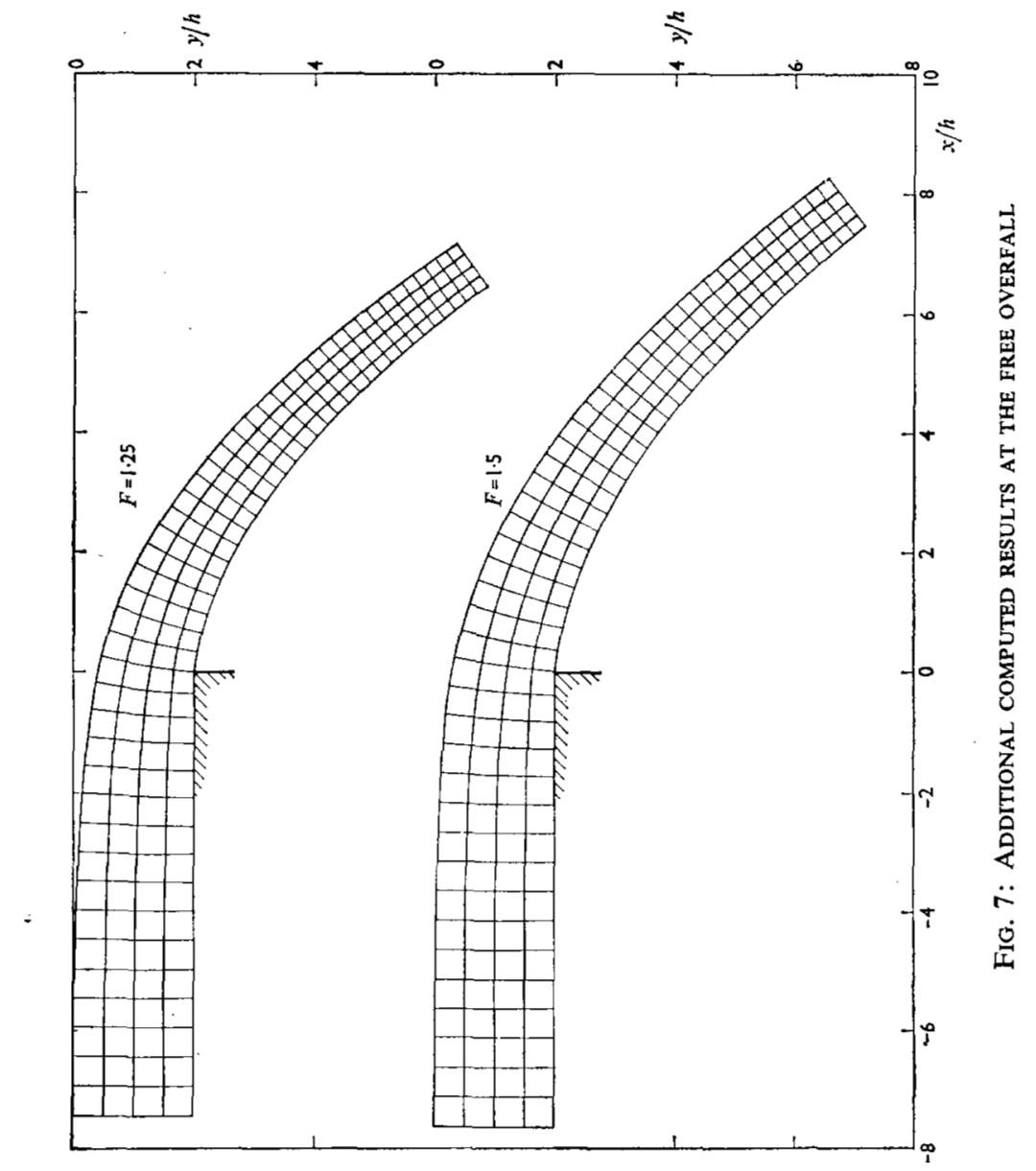


was so wide as to make interpolation difficult; two intermediate cases $(F=1.25$ and $F=1.5$ ) had therefore been calculated, and the results were shown in Fig. 7. These solutions gave sufficient additional information for the variation of $d_{\mathrm{c}} / h$ with $F$ to be plotted on Fig. 8; the empirical equation

$$
d_{\mathrm{c}} / h=1-0.28 F^{-1.75}
$$

was found to yield values which in every case lay within $\frac{1}{2} \%$ of the calculated ones.

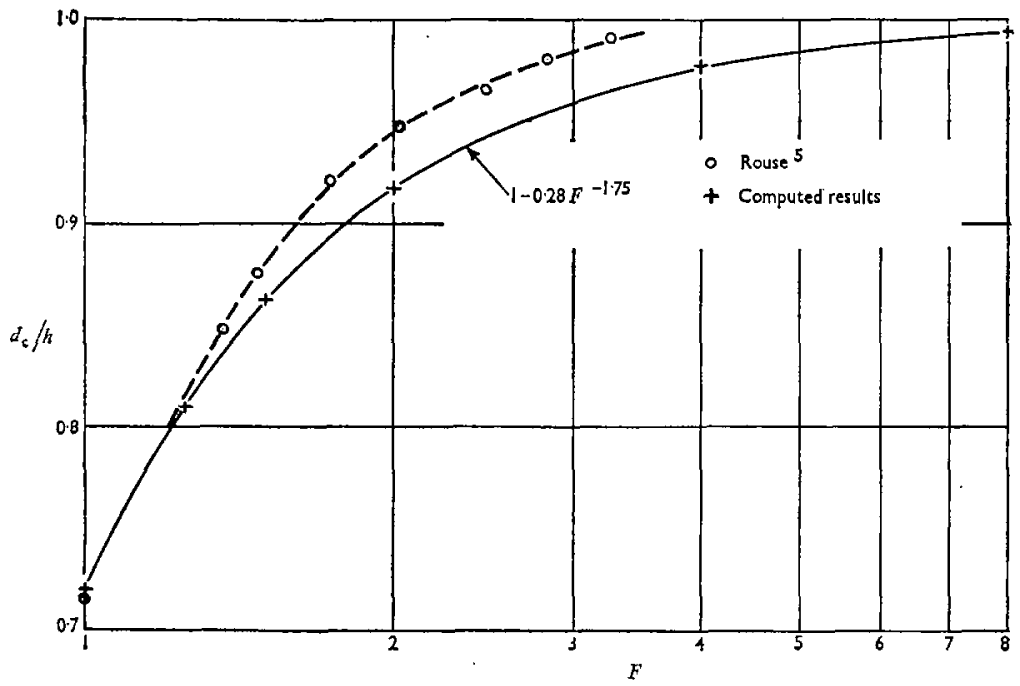

Fig. 8: Variation of Depth at the brink with Froude nUmber

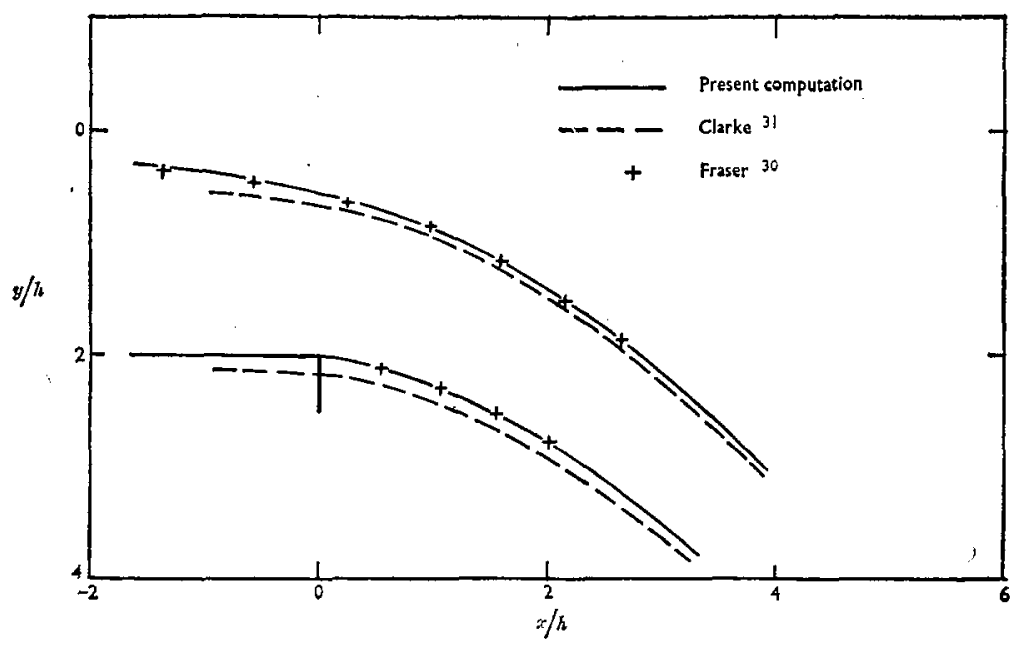

Fig. 9: Comparison of Calculated profiles, $F=1$ 
41. The Author was interested to learn of the work at the Hydraulics Research Station on the use of the overfall as a gauging device, and wished Dr Brewer and Mr Harrison every success in their experiments.

42. Comparison of the present solution with alternative theoretical solutions had become possible by virtue of private communications received from $\mathrm{Dr} W$. B. Fraser (the University of Sydney, Sydney, N.S.W.) and from Mr N. S. Clarke (the University of Cambridge). Dr Fraser has provided co-ordinates computed by the use of an integral equation ${ }^{30}$ and, by a fortunate coincidence, had chosen a step length which facilitated direct comparison of computed values. Although his solution did not extend very far, the agreement between his co-ordinates and the present solution was generally extremely good, as indicated on Fig. 9. Mr Clarke had used an analytical technique in which two asymptotic solutions, one of them valid upstream, and the other downstream, were matched to give a complete solution. ${ }^{31}$

43. Professor Strelkoff had rightly drawn attention to the usefulness of separating the effects of streamline curvature, fluid resistance, and gravitational effects in open channel flow. His analysis leading to Fig. 6, and the deduction from that diagram that the discharge was the maximum possible at a given head, was particularly elegant. Professor Strelkoff was correct in his observation that the control section of the computed solution for $F=1$ was infinitely far upstream; the calculations had in fact extended further upstream than the region covered in the published figures, terminating with $d=h$ at about $x=-11 h$.

\section{REFERENCES}

7. ACTon, J. E. A computer programme for the analysis of the effects of torsion. Concr. constr. Engng 1965, 60 (Aug.), 285-294.

8. JAEGer C. Hauteur d'eau à l'extrémité d'un long déversoir. Houille blanche, $1949,3(6)$.

9. JAEGer C. De l'impulsion totale et de ses rapports avec l'energie totale d'un courant à surface libre. Rev. gen. Hydraul., 1947 (Jan.-Feb.), 12-19; (May-June), 143-151.

10. SCHRODER R. Untersuchungen über diskontinuierliche Abflussvorgänge in Freispigelgerinnen. Doctoral Thesis, Berlin Technical University, 1947.

11. JAEger C. Engineering Fluid Mechanics. Glasgow, Blackie and Son, 1956. Pp. 114-117.

12. Bleines W. Berechnung des überfalls über das scharfkantige Plattenwehr auf Grund des Extremalprinzips. Wasserwirtschaft, Stuttg., 1952-53, 43 (4).

13. SChroder R. Geschwindigkeitsvertelung und Energieumwandlung in voll turbulenten Wasserströmungen. Wasserwirtschaft, Wien, 1958, 58 (July), $268-274$.

14. Carstens M. R. Free-overflow has rapidly varying characteristics. Civ. Engng, 1955, 25 (June) 64-65.

15. Delleur J. W., Dooge J. C. I. and Gent K. W. Influence of slope and roughness of the free overfall. Proc. Amer. Soc. civ. Engrs, 1956, 82, HY4 (Aug.), Paper 1038, 30-35.

16. PADER F. Sulla chiamata di sbocco in canale a fondo declive. Energia elett., $1956(8), 792-800$.

17. PADERI F. Sulla chiamata di sbocco in canale a fondo acclive. Energia elett., 1959 (10), 883-888.

18. Veronese A. Rilieve sperimentale sugli sbocchi liberi. Energia elett., 1948, 25 (Dec.) 638-641.

19. Replogle J. A. Discussion of 'End depth at a drop in trapezoid channels'. Proc. Amer. Soc. civ. Engrs, 1962, 88, HY2 (March), 161-165.

20. PAderi F. Misuratore di portata a chiamata da gradino di fondo in un canale. L'Acqua, 1964, no. 2 (March-April), 29-41. 
21. Carstens M. R. and Carter R. W. Discussion of 'Hydraulics of the free overfall'. Proc. Amer. Soc. civ. Engrs, 1955, 81 (June), Sep. No. 719, 18-28.

22. Kandaswamy P. K. and Rouse H. Characteristics of flow over terminal weirs and sills. Proc. Amer. Soc. civ. Engrs, 1957, 83, HY4 (Aug.), Paper 1345.

23. Hamid H. I. Discussion of 'End depth at a drop in trapezoidal channels'. Proc. Amer. Soc. civ. Engrs, 1962, 88, HY1 (Jan.), 133-136.

24. Strelkofr T. Solution of highly curvilinear gravity flows. Proc. Amer. Soc. civ. Engrs, 1964, 90, EM3 (June), 195-221.

25. BAKHMETEFF B. Hydraulics of Open Channels. New York, McGraw-Hill, 1932.

26. LAUCK A. Der Úberfall über ein Wehr. Z. angew. Math. Phys., 1925, 5, 1-16.

27. Cassidy J. Spillway Discharge at other than Design Head. Doctoral thesis, State University of Iowa, 1962.

28. Dumitrescu D. Die Strömung schwerer Flüssigkeiten mit freier Oberflache in senkrechter Ebene. Rev. Mec. appl., 1960, 5 (4), 457-482.

29. Watters G. and Street R. Two dimensional flow over sills in open channels. Proc. Amer. Soc. civ. Engrs, 1964, 90, HY4 (July), 107-140.

30. FrazER W. B. Gravity Deflected Jets in Two-dimensional Flow. Thesis, University of Canterbury, New Zealand, May 1961.

31. Clarke N. S. On two-dimensional inviscid flow in a waterfall. J. Fluid Mechs, $1965,22(2), 359-369$. 